\title{
Fracture test of a Gothic ribbed vault
}

\author{
J.C. Palacios, R. Martín, J.I. Hernando, D. Sanz, M.A. Alonso \& A. Aznar \\ E.T.S. of Architecture. Technical University of Madrid, Spain.
}

\begin{abstract}
A Gothic ribbed vault has been built at the School of Architecture of Madrid in order to investigate the construction complexities of this kind of vaults. The ribbed vault is described in the manuscript of Alonso de Vandelvira, and its shape was reconstructed making using the drawings this architect from the $16^{\text {th }}$ century. The fracture test was carried on by loading the central keystone of the vault until its collapse took place. The experiment was filmed and by doing so, it was possible to observe the failure mechanism of the vault. At the same time, it was interesting to compare this collapse experience with the results obtained using two different methods. First, a stability calculation was carried out through graphic statics, and secondly a calculation was performed using the rigid-block analysis method. The focus of this paper is to show and analyze the results of both studies.
\end{abstract}

\section{INTRODUCTION}

A unique experience has taken place in Madrid's School of Architecture: the fracture test of a Gothic ribbed vault. The vault has been built in the framework of a new academic discipline called "Gothic Construction Workshop" carried on by the Department of Construction and Architectural Technology. The workshop aims at building real Gothic vaults so as to attain a deeper knowledge of the construction complexity of this type of vaulting structures.

The selected vault was the one depicted in the manuscript by Alonso de Vandelvira (Palacios, 2009). The shape of the vault was reconstructed from the drawings done by this architect in the $16^{\text {th }}$ century: a somehow unique "Gothic" vault, since it is spherical. Its conventional structure consists of a couple of diagonal arches, eight tiercerons and four perimetral arches, all designed with the required bending to shape a spherical vault. It is precisely this round shape what allows to form, at the very centre of the vault and with secondary ribs, an extremely original drawing consisting of two concentric wheels which emphasize its spherical nature (Fig. 1).
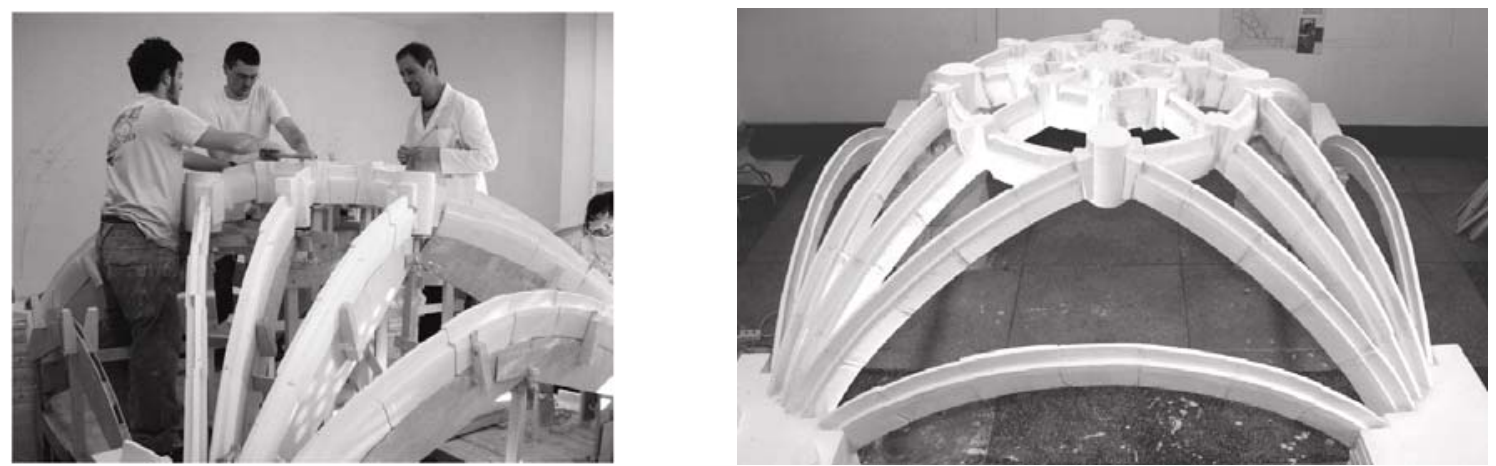

Figure 1. Construction process (left), and finished vault before fracture test (right). 
During construction, there were many unexpected problems which had to be faced, e.g. the difficulty to achieve the arches' flatness, which implied the perfect and consecutive alignment of the voussoirs. Regarding this issue, foreseeing the joints in between the voussoirs and their correct finishing proved to be a construction aspect of the great importance. To achieve the correct alignment of the voussoirs, they had to be placed separately, that is, leaving between them a few millimetres wide joint to be filled up later with a type of mortar. This was carried out with a clay mortar paste, quite dry, applied directly onto one of the sides; the next voussoir was then placed as in bond masonry, adjusting it to the previous one and removing the extra paste. In spite of taking some precautions, the arches showed some ostensive imperfections.

Those deficiencies nurtured the suspicion that, when supporting the load, the vault might collapse by flexure of one of the arches in the perpendicular direction to the directress' plan, rather than due to a flexure failure in this plan. In case a breaking of that type happened, the decision was to scan the vault prior to performing the test so as to find the construction failures (Fig. 2).

Nevertheless, the test to be carried out made us question the stability of the studied vault. The important fact before setting off the experiment was to know, though approximately, the precise load to apply to the central key that would provoke the vault's collapse. Could this vital question be previously answered by means of calculations or should we get to know this magnitude empirically, by gradually loading the vault up to breaking it? Two parallel studies were developed using both a graphic static method and a rigid-block analysis method in order to set the collapse load of the vault. Both of them are further expanded in this paper.

\section{LABORATORY TESTS}

Before starting the study, we needed to know the material with which the vault had been built. The laboratory tests performed showed the following data: the resistance to simple compression reached $10.64 \mathrm{~N} / \mathrm{mm} 2$, approximately like a brick, and its tensile strength, obtained by a flexure test, when breaking was $4.86 \mathrm{~N} / \mathrm{mm} 2$ and it showed a plastic period equal to null.

Later on, another bending test was applied to two pieces joined by the mortar which had been used in the joints. The tensile strength test result lowered to $1.30 \mathrm{~N} / \mathrm{mm} 2$. The outcome was probably due to the use of a rather dry paste, which prevented a greater bong between the voussoir sides. This fact suggested that the vault would have the same behaviour in real life: the voussoirs were not joined to one another and the breaking of an arch would occur after the respective plastic spherical hinges among voussoirs had been formed. Finally, density measuring was carried out: $0.95 \mathrm{~kg} / \mathrm{dm} 3$, lower than 1 , which means that the material, before water soaked, floats.
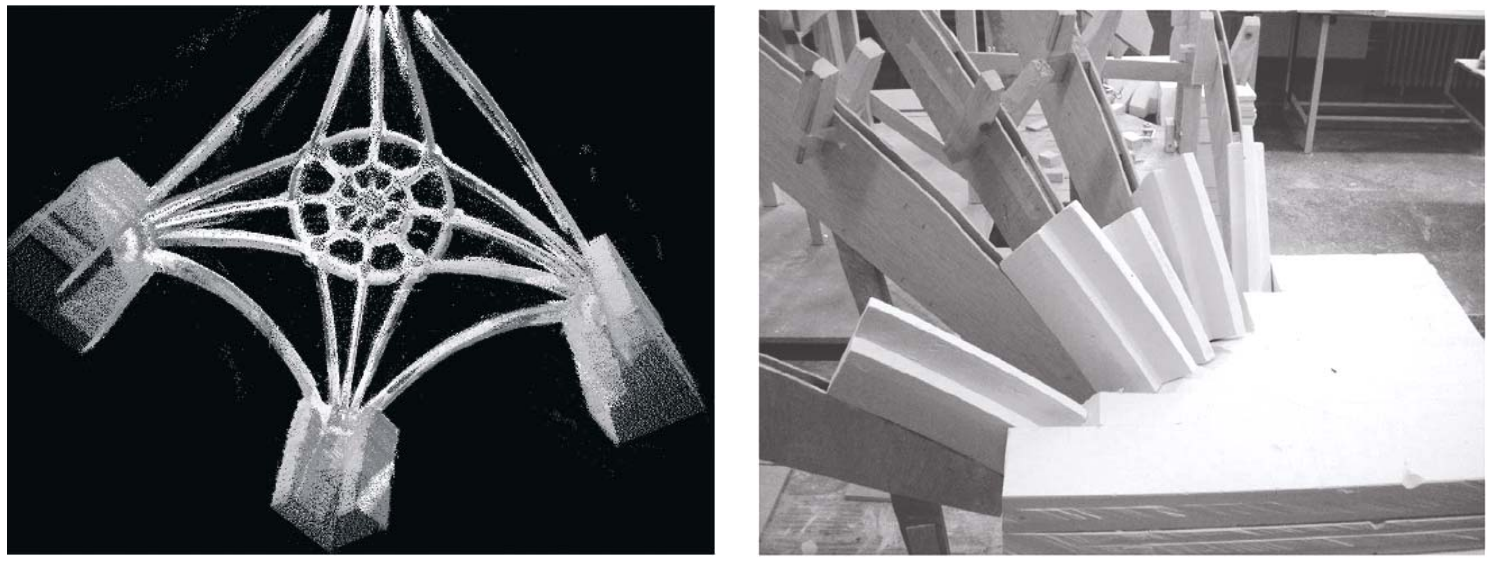

Figure 2. Scanned vault to obtain the actual geometry (left), and view of the tas de charge (right). 


\section{GRAPHIC STATIC ANALYSIS}

\subsection{General aspects on arch collapse}

In general, a masonry arch is a hyperstatic structure with infinite pressure lines contained in its mass (infinite stability solutions). A plastic spherical hinge is produced when the pressure line reaches the mass perimeter. This spherical hinge implies that the line cannot come out of the mass, and an equivalent to the plastic moment has been reached. As the spherical hinge is formed, a redundancy of the structure is eliminated, and the degree of hyperstatism diminishes. When three spherical hinges are formed, all redundancies are eliminated, and the structure is isostatic; that is, there is only one possible equilibrium solution and one pressure line in the mass interior. When the four alternative spherical hinges are produced, the structure becomes a mechanism and collapse occurs (Heyman, 1995). This process can be observed in Fig. 3: when increasing the load, the tangent point of the pressure line with the arch intrados (plastic spherical hinge) moves towards the key stone. At the same time as the resultant at the springer rises towards the extrados. The collapse is produced when the spherical hinge is placed in B"', when another spherical hinge appears in $\mathrm{C}$, and the group of $\mathrm{A}, \mathrm{B}$ '" and $\mathrm{C}$, produce a mechanism which causes the collapse of the structure.

\subsection{Analysis methodology}

In order to study the vault collapse (Fig. 2) the following hypotheses have been established:

1. The strain produced at the vault until the moment of collapse is considered insignificant, and hence the geometrical modification produced is not taken into account.

2. The vault is perfectly symmetrical and homogeneous. Although this hypothesis is not true, it is considered so in order to simplify the calculations.

3. The tensile strength present in the structure due to the joint mortar is not considered. This implies a conservative hypothesis, that is, the real collapse load will be greater than the resulting one in the present analysis.

To study the collapse analysis of the three-dimensional structure of the vault, it has been divided into equivalent homologous arches: diagonal and tiercerons (with ridge ribs). Each of these has been separately studied so as to determine the individual collapse load. The process developed when analyzing an individual arch consists in loading the arch on its precise key point, so that firstly, three spherical hinges are formed (isostatic structure), and later a fourth one is produced with the subsequent mechanism occurrence, so that the collapse load of the arch is determined. The global vault collapse load has been determined as the addition of the individual collapse loads of each arch. The thrust of the key on each of the arches has been established to be located at the same common point in the whole vault (the centre point of the central key extrados). This condition is needed to produce a global equilibrium of all arches in the threedimensional structure.
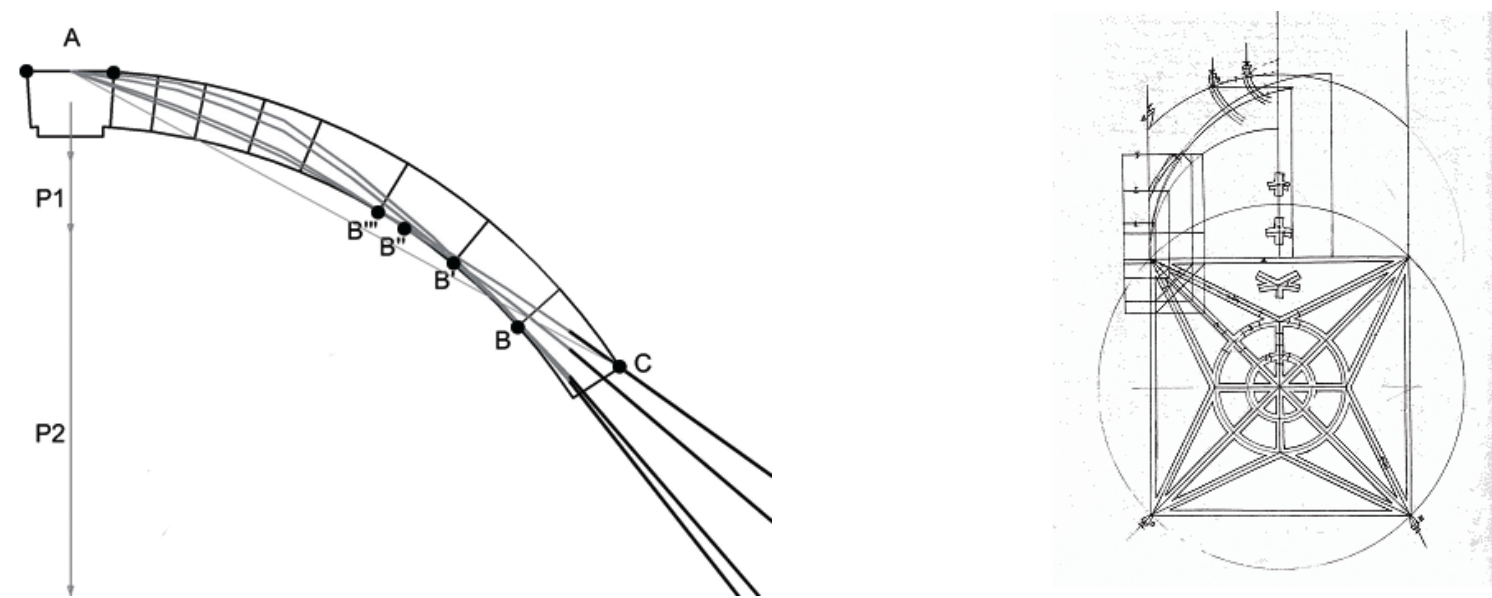

Figure 3. Collapse process' of the vault by increasing the load (left), and Vandelvira's design (right) 


\subsection{Collapse analysis of the diagonal arches}

In order to determine the collapse load of the diagonal arch, the pressure line originating the four alternative spherical hinges (and hence a mechanism) has been found. It is an iterative process; that is, it is based on a polygon of random stresses which is later adjusted, while at the same time increasing the load until a pressure line alternatively tangent to the arch's extrados and intrados is obtained, which, in turn, produces a mechanism. The final result shows that the arch is capable of withstanding a maximum load of $0.22 \mathrm{kN}$ before the collapse is produced. The horizontal thrust produced at the key point is of $0.33 \mathrm{kN}$ and the resulting thrust transmitted to the springer is of $0.40 \mathrm{kN}$ (Fig. 4).

\subsection{Collapse analysis of the tierceron arches and the ribs}

This is a more complex case than the previous one, because the group of ribs and tiercerons together has been analyzed. In order to do so, an auxiliary view is needed so that both arches are studied on the same plane. In a similar way, the transmitted thrusts from the rib in key point $\mathrm{C} 2$ need to be decomposed and divided toward the tierceron arches. Due to this, the auxiliary view in which the arches have been placed on the same plane has been carried out revolving on the vertical axe situated at the $\mathrm{C} 2 \mathrm{key}$.

The pressure line has been determined starting from the thrust $(\mathrm{H})$ applying point, at the centre of the extrados of the central key $\mathrm{C} 1$ (common point to the arches thrusts forming that unit), and following a repetitive process. However, in this case, the study started by a greater load than that of collapse (and where the equilibrium is impossible), and it has been reduced (together with the $\mathrm{H}$ thrust adjustment) until the collapse load could be obtained when the spherical hinges needed have been produced. The first load attempts $(0.10 \mathrm{kN})$ have not found a pressure line in the interior of the masonry. As the specific load on the key point is diminished, the gravity centre is displaced towards the springer of the tierceron arch. In addition, as the H thrust diminishes at the key, the final resulting slope of the arch increases. All this helps in progressively tracing a thrust line inside the perimeter of the arch.

The final result shows that the group formed by the ridge ribs and two tiercerons can withstand a maximum load of $0.05 \mathrm{kN}$ before the collapse is produced. The thrust $(\mathrm{H})$ produced in the key is of $0.21 \mathrm{kN}$ and the resulting thrust (R) transmitted to the springer of the tiercerons is of $0.28 \mathrm{kN}$ (Fig. 4).

\subsection{Analysis of the vault global collapse}

Once the arches have been individually studied, it is possible to estimate the global collapse load for the three-dimensional structure. Since the diagonal arches support a maximum load of $0.22 \mathrm{kN}$, and the ridge rib and tierceron arch group collapse at $0.05 \mathrm{kN}$, it can be concluded that the global collapse load of the group formed by diagonal arches, ribs and tiercerons is of 0.54 $\mathrm{kN}$.

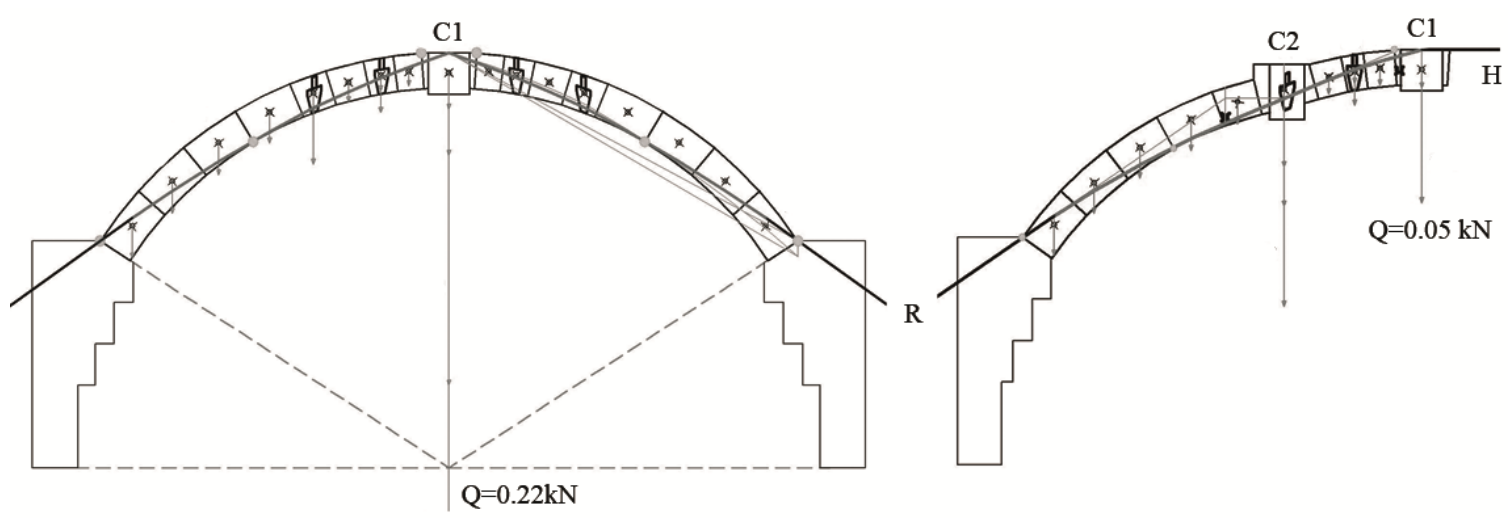

Figure 4. Analysis of diagonal arch (left), and tierceron (right) 


\section{LIMIT ANALYSIS OF FLAT LINEAR STRUCTURES MADE OF RIGID BLOCKS}

\subsection{General aspects}

As it is well known, plastic calculation of the indicated typology is reduced to a mathematical problem of linear programming or easily linearizable:

$\max (\lambda)$; subject to: $\lambda \mathrm{w}^{+} \mathrm{q}=\mathrm{H} \cdot \mathrm{s} ; \mathrm{g}_{\mathrm{i}}(\mathrm{s})<1$

The aim is to find the maximum load factor $(\lambda)$ so that the structure collapse begins, satisfying the equilibrium conditions $(\lambda \mathrm{w}+\mathrm{q}=\mathrm{H} \cdot \mathrm{s})$ together with the formulae of interaction among stresses $\left(g_{i}(s)<1\right)$. Such interaction formulae $\left(g_{i}(s)<1\right)$ are the ones corresponding to the joint strength for the pair of concomitant stresses N,M. These fluency surfaces are similar to Fig. 5, obtained for a rectangular section without tensile strength and assuming a rectangular distribution of stresses similar to the one normally adopted in the concrete section studies. The reasons for the deletion of the tensile strength of the joints have already been explained. It is also known that in this type of structure collapse is produced with axial stress values much smaller than the axial which exhausts the section, and therefore, the interaction surfaces of Fig. 5 is substituted by its tangent in its origin. In physics term, this is reduced to imply that the compressive strength in the joints is not delimited, whereas, it has no tensile strength.

The effect of these simplifications will be measured once the analysis is finished, since it is not possible to ensure that they are still valid for a scaled model and material (plaster) different than the one used traditionally for this typology.

In this way, the problem has been reduced to one of linear programming (LP):

1. The mathematical theory of linear programming is of immediate application. A consequence of the mathematical formulae applied to the problem is that it necessarily needs to follow a normality rule or Von Mises flow rule (the mathematical model describes a physical problem of associated plasticity).

2. There are very steady and efficient algorithms to solve such problems (Vanderbei, 2001).

3. These algorithms, apart from giving a solution to the original problem, supply a solution to the second problem which in LP is called dual. The solution to this problem has a simple physical interpretation: it represents the virtual collapse mode associated to the maximum load factor which triggers the system collapse.

\subsection{Livesley formulation}

The physical interpretation of linearization proposed for the $\mathrm{N} / \mathrm{M}$ interaction formulae (Livesley, 1853) permits the performance of a fruitful particularization of the algorithm, used by Livesley and is the one used in the later analysis. Observing the instrumental character of the forces (s components) there is a variable change where the standard stress pair $\mathrm{N}$ and $\mathrm{M}$ is substituted by two new loads $\mathrm{N}_{\mathrm{i}}$ and $\mathrm{N}_{\mathrm{j}}$ applied on each of the vertexes of the ij joint. For these new variables, the proposed linearization for the restrictions is reduced to: $\mathrm{N}_{\mathrm{i}}>0$ y $\mathrm{N}_{\mathrm{j}}>0$. Fig. 5 represents the loads of one of the elements of the arch and its equilibrium equations. Obviously, to describe the state of the joint at the $\mathrm{N}_{\mathrm{i}}, \mathrm{N}_{\mathrm{j}}$ loads, the shear stress $\mathrm{V}_{\mathrm{ij}}$ should be added.
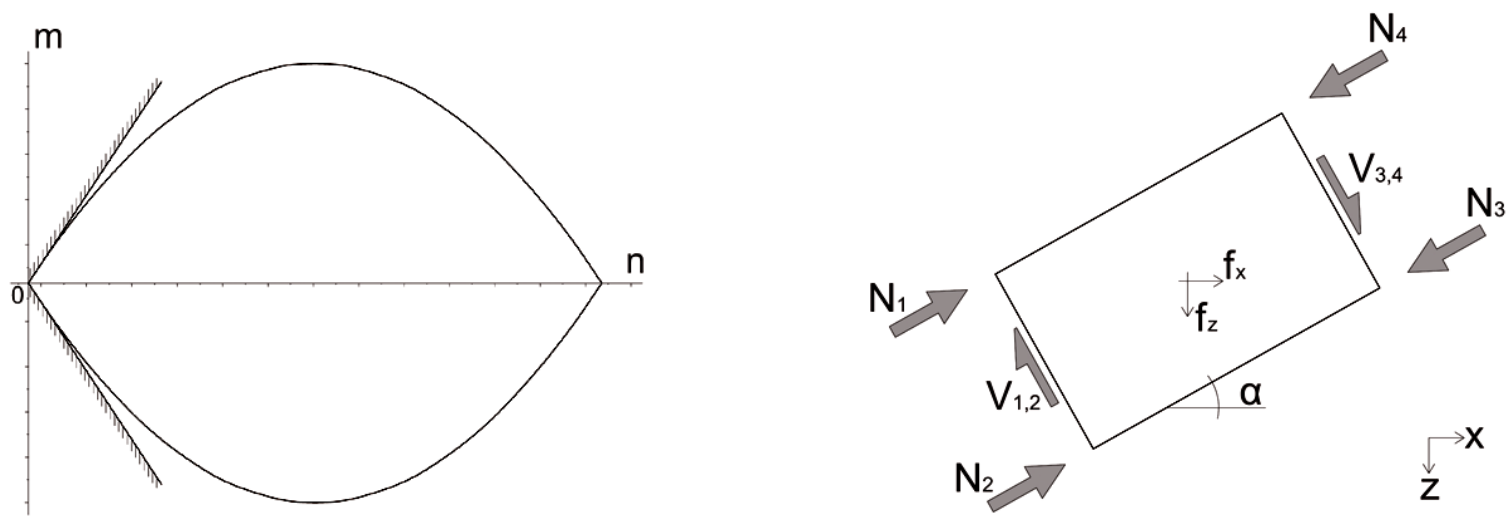

Figure 5. Surface of interaction and linearization (left), and equilibrium of a rectangular block (right) 


\subsection{Friction. Non linear flat structures and three-dimensional masonry structures}

With the formulation proposed so far, the sliding between two blocks is hindered. As no restrictions for the instrumental values $\mathrm{V}_{\mathrm{ij}}$ are included, these can obtain any value preventing the corresponding "dual" deformation.

The model can be "enlarged" by adding restrictions to the shear stresses derived from the classical friction formulation of Coulomb: $\mathrm{V}_{\mathrm{ij}}<\mu\left(\mathrm{N}_{\mathrm{i}}+\mathrm{N}_{\mathrm{j}}\right) ;-\mathrm{V}_{\mathrm{ij}}<\mu\left(\mathrm{N}_{\mathrm{i}}+\mathrm{N}_{\mathrm{j}}\right)$.

Clearly, these new restrictions are linear, and hence, the mathematical problem continues to belong to the category of LP. An immediate/necessary consequence is that the new formulation follows the Von Mises flow rule. It is experimentally proved that friction does not follow this rule (it is a problem of non associated plasticity) and produces several consequences:

1. The solution to the dual problem does not correctly represent the system collapse. A displacement in a joint needs an expansion in the same proportion of $\mu$. This is a minor consequence with a heuristic solution (Livesley, 1853). An experimental demonstration that shows that Von Mises rule does not describe friction is that the deformation predicted is not observed.

2. The theorems of the limit analysis are no longer valid.

3. LP algorithms overestimate the load factor $(\lambda)$ for which collapse starts (this is obvious since in the problem formulation the maximum load factor mathematically possible is searched, and not the physically possible).

The later does not only limit the range of the application of LP algorithms: it also limits the results in the graphic static of the previous point.

In masonry linear structures, such as arches, the $\mu$ coefficient is high enough not to produce failures due to sliding, or, in case they happen, the effect of assuming that these sliding follows the Von Mises flow rule, does not significantly alter the load factor value, which experimentally collapses the structure (this is not the case in bonded masonry).

To sum up, in the vault analysis, the sliding of the joints was limited by adopting a friction coefficient, which was considered appropriate as no experimental data was found. The collapse mode observed during the test coincided with the mechanism obtained preventing sliding, which in turn, makes the initial hypothesis valid.

If the proposed formulation is to be applied to the tested specimen, it is necessary to extend the result to a spatial system. The difficulties this work faces (Ferris, 2001), are all related to the problems with friction. In addition to these mathematical obstacles of the problem, not identified by Livesley (Livesley, 1853), the friction modelling in a flat spatial joint is added. In linear flat joints the position of the friction stress is insignificant (and therefore the position of the axial) however, the same does not occur with a flat joint, where friction has to face the slidings in any direction, and basically, the torsion rotations of each block regarding the adjacent ones: it is not clear even how to represent the axial stresses inside the joint.

\subsection{Model proposed for the vault analysis}

The spatial performance of the whole has been studied, adopting the following model:

1. Each arch is modelled individually like if it were a flat structure. In this way, the friction uncertainties are not introduced. Particularly, the possible torsion rotations among blocks are restricted. This hypothesis proved correct, because the deformations are not observed in the test video.

2. To consider the spatial component of the vault, the voussoirs common to different arches are joined substituting the equations of partial equilibrium for each plane by the corresponding equilibrium equations in the volume space (Fig. 6).

If a calculation program to solve the Livesley plane problem is used, the previous ridge ribs are easily introduced: e.g. if the vertical movement of the key block of both diagonal arches, is to be joined, the process would be to add the arbitrary force $+-f_{z}$ to the stresses acting on every block representing the same voussoir (in this way, the equilibrium equation of the vertical forces of the volume in space is being produced). Fig. 6 shows the precise process followed for a key block where three arches coincide. 

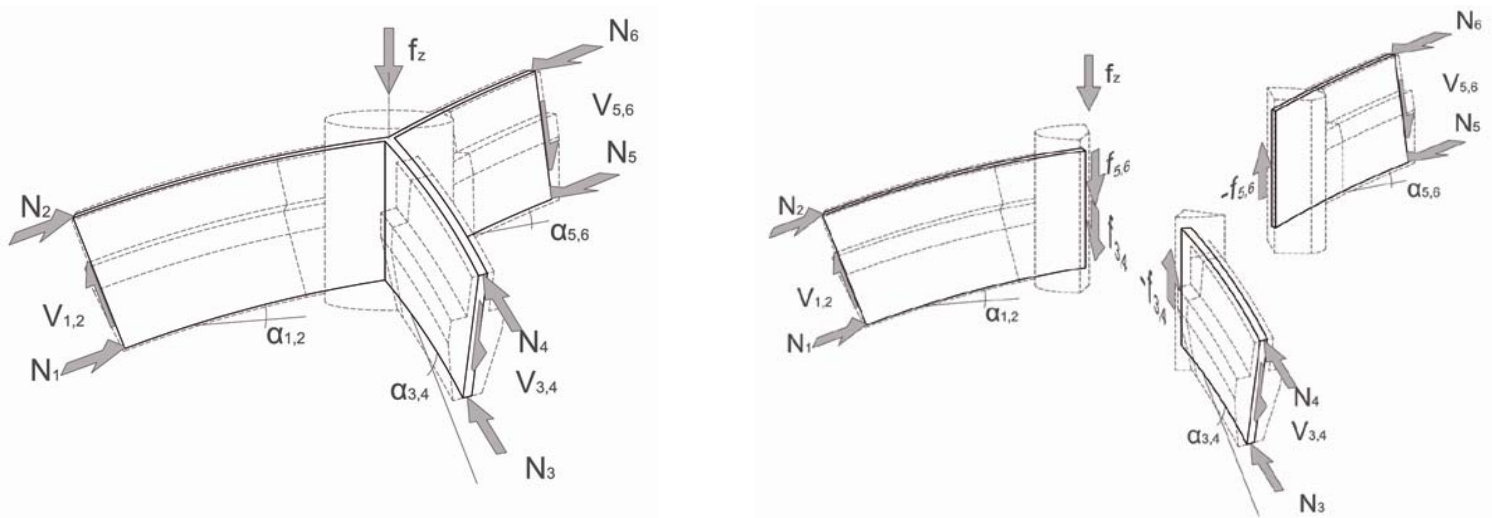

Figure 6: Equilibrium for the key block of three arches (left), physical interpretation of the instrumental variables $\mathrm{f}_{\mathrm{z} 34}$ and $\mathrm{f}_{\mathrm{z} 56}$ (right)

Similarly, the horizontal movement of the common elements can be joined. However, in this case, the $+-f_{x}$ forces which have to be added will be affected by the sine $(\beta)$ factors and/or the corresponding cosine $(\beta)$. At the same time, the horizontal movement of the volume twists can be joined, introducing the instrumental moments needed. The key blocks of all arches were joined following the procedure previously stated. The circular rings were omitted in the final analysis because it was observed in previous models that they were under tensile strength, and therefore, they just complicated the results interpretation. Fig. 7 shows the collapse mechanism predicted for the model.

\subsection{Final considerations}

1. Compressive strength of the sections: it can be easily checked that for the compressive strength value obtained in the lab and the load for collapsing the structure in the most unfavourable section, $\mathrm{N}_{\mathrm{E}} / \mathrm{N}_{\mathrm{R}}$ is of $10^{-3}$. Therefore, it is plausible to assume the compressive strength as infinite.

2. Tensile strength of the sections: with the model proposed, that is, assuming that tensile strength is inexistent, the load producing the structure to collapse is $0.40 \mathrm{kN}$. For this load level, the maximum axial in a joint is $0.126 \mathrm{kN}$ and its maximum eccentricity $0.154 / 2 \mathrm{~m}$ (half the height of the ribs). With the proposed model, the resulting value should not exceed the rib section.

3. Transversal bending effect: assuming an initial $\mathrm{e}_{\mathrm{o}}$ eccentricity/imperfection of 0.04 in perpendicular direction, (and taking simply and in conservative way $\mathrm{M}_{\mathrm{y}, \mathrm{Ed}} / \mathrm{M}_{\mathrm{y}, \mathrm{el}, \mathrm{Rd}}$ $\left.+\mathrm{M}_{\mathrm{z}, \mathrm{Ed}} / \mathrm{M}_{\mathrm{z}, \mathrm{el}, \mathrm{Rd}}<1\right)$ the collapse is produced at $1.30 \mathrm{kN}$. The possible secondary effects for this load level are negligible $\left(\mathrm{P} / \mathrm{P}_{\text {cri }}\right.$ is of 0.015$)$.

4. Unknown the joint mortar tensile strength, the only conclusion that can be set, is that the collapse load of the vault is between $0.40 \mathrm{kN}$ and $1.30 \mathrm{kN}$.
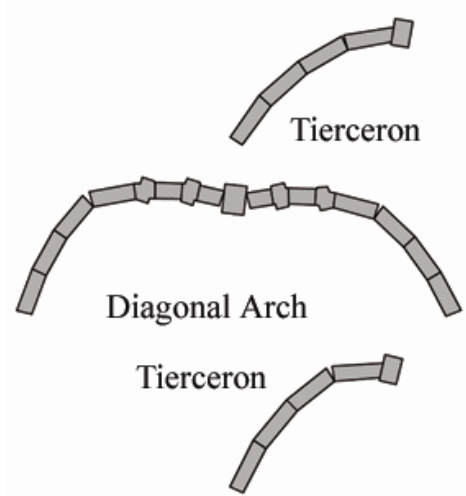

Figure 7: Collapse mechanism
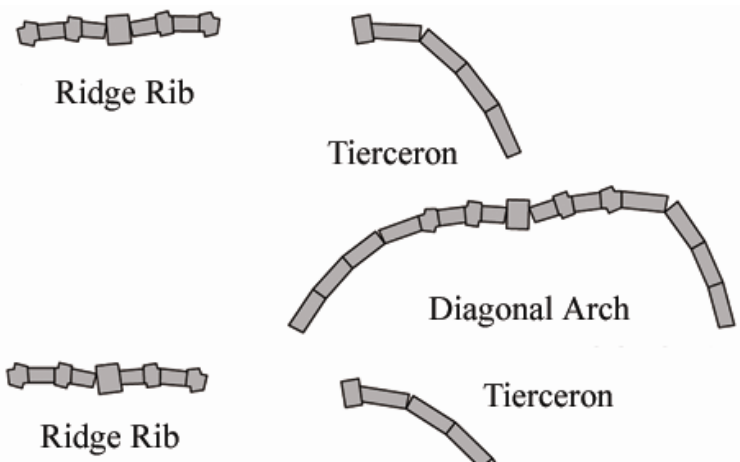

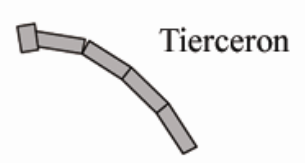




\section{FRACTURE TEST}

The fracture test consisted of loading the central key with a certain weight up to induce the collapse. Previously, we had marked the joints of each arch where it was supposed that a plastic spherical hinge would be formed. The vault supported a maximum load of $0.85 \mathrm{kN}$, and it collapsed with the following load of $0.90 \mathrm{kN}$. The experiment was filmed and it has provided the opportunity of watching a vault collapse, step by step. It was a unique opportunity to physically watch the formation of the plastic spherical hinges, and the cracks opening when some voussoirs rotated around the others. The general collapse movement of the vault consisted of two main parts. First of all, the lower part of diagonal arches and tiercerons started to move outwards, giving way to the central part of the vault fall down. Finally, these arches returned and moved inwards, falling down into the central part of the vault (Fig. 8).

\section{CONCLUSIONS}

First of all, a basic principle of masonry structure analysis is confirmed: the compressive strength of the material is not a critical aspect for the equilibrium, and it may be assumed that a failure produced by a high compressive load will not take place.

Tensile strength of the joint mortar, although low, is a fundamental parameter to estimate the load producing the structure collapse. If the tensile strength of the joint mortar is null, the equilibrium condition is limited to the continuation of the pressure line in the interior of the masonry. When the thrust line is situated slightly outside of the arch perimeter, tension stress occurs on the opposite side of the pieces. If the joint mortar cannot support any tensile strength, a crack is produced. But when the mortar is able to support tensile strength, these tensions may be absorbed, so the actual collapse load of the structure is greater.

Both analyses are very conservative, since the do not consider any tensile strength of the joint mortar. Analysis by graphic static of strained three-dimensional structures is very complex, as there are a great number of variables. Simplifying hypotheses have been established so that a feasible development could be conducted. The result is much smaller $(0.54 \mathrm{kN})$ than the experimental collapse load $(0.90 \mathrm{kN})$. Analysis of rigid blocks gives a quite imprecise result $(0.40$ $\mathrm{kN}$ to $1.30 \mathrm{kN}$ ). The comparison with the experimental result will allow to obtain more precise results in future analyses, specially if the joint mortar cannot support tensile strength.

Finally, the experiment has provided the opportunity of filming a vault collapse. This has been of great importance because it allowed watching the arches cracks and the formation of the plastic spherical hinges just before collapse.

\section{REFERENCES}

Ferris, M. Tin-Loi. F. 2001. Limit analysis of frictional block assemblies as a mathematical program with complementarity constraints. International Journal of Mechanical Sciences.

Heyman, J. 1995. The stone skeleton. Cambridge University Press.

Livesley, R.K. 1978. Limit analysis of structures formed from rigid blocks. Int J Number Methods Eng. Palacios, J.C. 2009. La cantería medieval. Madrid: Munilla Lería

Vanderbei, R. 2001. Linear programming: foundations and extensions. Boston: Kluwer Academic.
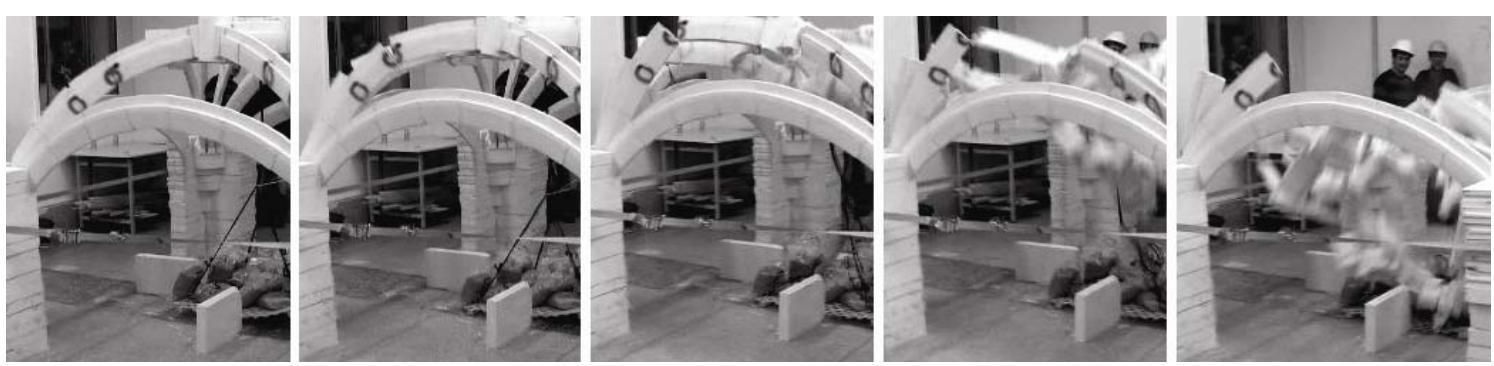

Figure 8: Collapse images 